\title{
Using barometric time series of the IMS infrasound network for a global analysis of thermally induced atmospheric tides
}

\author{
Patrick Hupe, Lars Ceranna, and Christoph Pilger \\ Bundesanstalt für Geowissenschaften und Rohstoffe, Hanover, 30655, Germany
}

Correspondence: Patrick Hupe (patrick.hupe@bgr.de)

Received: 19 December 2017 - Discussion started: 22 December 2017

Revised: 8 March 2018 - Accepted: 14 March 2018 - Published: 10 April 2018

\begin{abstract}
The International Monitoring System (IMS) has been established to monitor compliance with the Comprehensive Nuclear-Test-Ban Treaty and comprises four technologies, one of which is infrasound. When fully established, the IMS infrasound network consists of 60 sites uniformly distributed around the globe. Besides its primary purpose of determining explosions in the atmosphere, the recorded data reveal information on other anthropogenic and natural infrasound sources. Furthermore, the almost continuous multiyear recordings of differential and absolute air pressure allow for analysing the atmospheric conditions. In this paper, spectral analysis tools are applied to derive atmospheric dynamics from barometric time series. Based on the solar atmospheric tides, a methodology for performing geographic and temporal variability analyses is presented, which is supposed to serve for upcoming studies related to atmospheric dynamics. The surplus value of using the IMS infrasound network data for such purposes is demonstrated by comparing the findings on the thermal tides with previous studies and the Modern-Era Retrospective analysis for Research and Applications Version 2 (MERRA-2), which represents the solar tides well in its surface pressure fields. Absolute air pressure recordings reveal geographical characteristics of atmospheric tides related to the solar day and even to the lunar day. We therefore claim the chosen methodology of using the IMS infrasound network to be applicable for global and temporal studies on specific atmospheric dynamics. Given the accuracy and high temporal resolution of the barometric data from the IMS infrasound network, interactions with gravity waves and planetary waves can be examined in future for refining the knowledge of atmospheric dynamics, e.g. the origin of tidal harmonics up to 9 cycles per day as found in the barometric data sets. Data assimilation in empirical models
\end{abstract}

of solar tides would be a valuable application of the IMS infrasound data.

\section{Introduction}

The International Monitoring System (IMS) was established to monitor compliance with the Comprehensive NuclearTest-Ban Treaty (CTBT) which aims to ban all kinds of nuclear explosions (CTBTO Preparatory Commission, 2017a). The IMS is dedicated to detecting explosions down to a threshold of $1 \mathrm{kt}$ TNT equivalent. Three waveform technologies, seismology, hydroacoustics, and infrasound, cover the entire range of conceivable explosion environments on Earth, which are underground, underwater, and atmospheric, respectively.

This study is based on the infrasound network component of the IMS. Besides nuclear monitoring, it also contributes to the project called Atmospheric dynamics Research InfraStructure in Europe (ARISE; Blanc et al., 2017). ARISE aims to design an infrastructure which combines atmospheric observation technologies, e.g. ground-based wind and temperature measurements (Le Pichon et al., 2015) with infrasound measurements, to retrieve 4-D information of the atmosphere. The objective of ARISE is to enhance weather forecasts and climate models through a more accurate knowledge of atmospheric dynamics in the middle atmosphere (Braathen, 2013; Blanc et al., 2017). The latter issue is of great importance, as gravity waves, tidal waves, and planetary waves transport energy and momentum. These waves, of which the majority originate in the troposphere, modify the circulation patterns by breaking in the stratosphere and mesosphere (Fritts and Alexander, 2003). In contrast, there 
is robust evidence that this variability forced in the middle atmosphere can lead to modifications of tropospheric circulation systems and therefore affects the weather (Baldwin and Dunkerton, 2001). Moreover, better knowledge of atmospheric dynamics is essential in the context of future verification of the CTBT.

With regard to the dynamics and their temporal and spatial variability in the troposphere, this study focuses on absolute air pressure recordings at the IMS infrasound arrays. The potential of infrasound sensors for broad band measurements and the detection of atmospheric dynamics was pointed out by Blanc et al. (2010). Several studies used infrasound measurements for investigating variations in the middle and upper atmosphere (e.g. Donn and Rind, 1972; Le Pichon et al., 2005; Assink et al., 2012; Smets and Evers, 2014). Here a methodology is described for systematically analysing geographic and temporal variability of atmospheric dynamics' features based on the IMS infrasound network. A similar approach was taken by Marty et al. (2010). We particularly focus on the atmospheric tides and consider up to 13 years of barometric data.

Tides can be traced to two excitation mechanisms (Chapman and Lindzen, 1970). The first is gravitational forcing by the Sun and the Moon. It is commonly known as cause of the periodic rise and fall of the sea level, i.e. the ocean tide, the period of which is related to the lunar day $(24 \mathrm{~h}$ and $50 \mathrm{~min}$ ). Since the gravitational pull of the Moon is considerably larger than that of the Sun (e.g. Thomson, 1882; Lindzen and Chapman, 1969), the tidal signature in air pressure data should be related to the lunar day. However, the predominating tidal harmonics found in air pressure recordings are clearly related to the solar day $(24 \mathrm{~h})$. Therefore, a second excitation mechanism must exist; it is thermal forcing by the Sun's radiation (Chapman and Lindzen, 1970). Unless otherwise stated, mentioning atmospheric and solar tides throughout this article primarily implies the thermally excited tides with periods related to the solar day. In particular, we focus on the diurnal $(24 \mathrm{~h})$, semi-diurnal $(12 \mathrm{~h})$, and terdiurnal tide $(8 \mathrm{~h})$ but we can also identify pressure oscillations with up to 9 cycles per day (cpd) by spectral analyses. The different harmonics result from periodic insolation absorption and latent heat release in various layers of the atmosphere (Forbes and Gillette, 1982). Non-linear wave interactions are considered as another source of the tidal harmonics, in particular those below a period of $12 \mathrm{~h}$ (Moudden and Forbes, 2013).

Moreover, one has to differentiate between migrating and non-migrating components of the aforementioned tides. The former propagate westward, following the apparent motion of the Sun, while the latter do not (Chapman and Lindzen, 1970). When Haurwitz (1965) identified non-migrating components in barometric recordings, he related them to the irregular distribution of land masses. Dai and Wang (1999) stated that the non-migrating tides can reach large amplitudes due to differences of sensible heat flux on land and sea, respectively. One prominent small-scale example caus- ing a local (non-migrating) diurnal oscillation is the land-sea breeze pattern (Chapman and Lindzen, 1970). In general, the migrating tides prevail over the non-migrating in terms of amplitude (Haurwitz, 1965). Insolation absorption by water vapour and ozone is seen as primary source of the migrating tides (Butler and Small, 1963; Chapman and Lindzen, 1970; Whiteman and Bian, 1996), but cloud effects, precipitation and latent heating are also considered to be a source of tidal variations, especially for the semi-diurnal tide in the tropics (Dai and Wang, 1999). In this study, we will not examine the different sources but rather the characteristics of the various tides detected within a global network.

The infrasound network of the IMS is described in more detail in Sect. 2. Section 3 deals with the selection of the data. Information on the evaluation tools applied is given in Sect. 5. Results on atmospheric tides are presented in Sect. 6. The discussion included is focused on the potential of the IMS infrasound network for geographic variability analyses in the context of our findings and previous studies on atmospheric tides. Whilst several of those studies addressed the tidal effects and characteristics in the middle (e.g. Forbes, 1984) and upper atmosphere (Forbes and Garrett, 1979; Forbes, 1990; Thayaparan, 1997; Zhao et al., 2005), we concentrate, for reasons of comparability, on tropospherebased observations and theories (e.g. Haurwitz, 1956; Kertz, 1956; Dai and Wang, 1999). We compare our results with the Modern-Era Retrospective analysis for Research and Applications Version 2 (MERRA-2), which is introduced in Sect. 4.

\section{The IMS infrasound network}

Infrasound is defined as the frequency range between approximately $3.3 \mathrm{mHz}$, i.e. the acoustic cut-off frequency, and the threshold of human-audible sound, which is approximately $20 \mathrm{~Hz}$. The acoustic cut-off frequency depends, among others, on altitude, temperature, and humidity. The same applies to the speed of sound at which infrasound can travel through the atmosphere over large distances (Evers and Haak, 2010). This feature is a result of minor attenuation within the abovementioned frequency range. Therefore, infrasound is highly applicable for detecting explosions. Moreover, ducting in the troposphere, in the stratosphere, and in the lower thermosphere contributes to the detection of explosions far away from the source (Drob et al., 2003). In the decades after World War II, the infrasound technology was already used to detect significant nuclear explosions in the atmosphere (Christie and Campus, 2010). In the late 1990s, the IMS infrasound network construction was initiated in terms of CTBT verification purposes to detect and locate even small explosions with a TNT equivalent of $1 \mathrm{kt}$ in the Earth's atmosphere. Its 60 stations are therefore more uniformly distributed than previous, smaller networks (Blanc et al., 2010). As of the end of November 2017, 49 stations (see Fig. 1) 


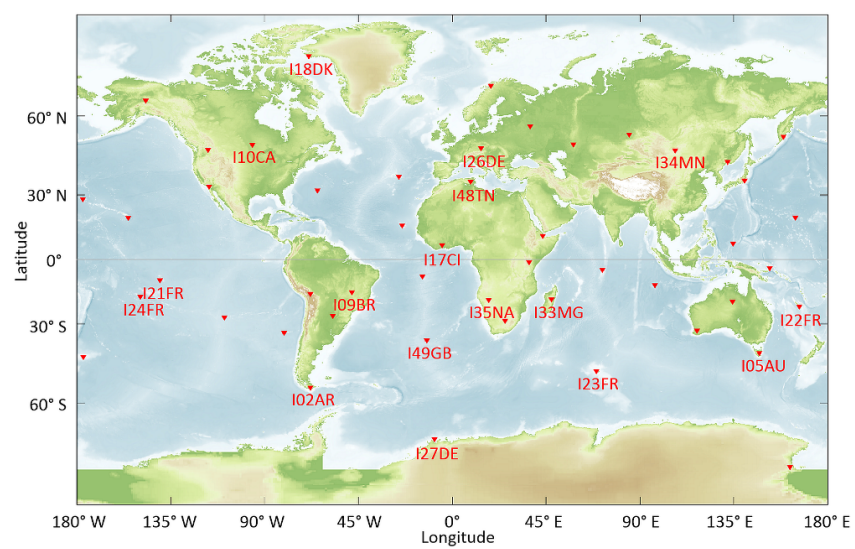

Figure 1. Station map of the IMS infrasound network as part of the CTBT verification regime. Each red triangle represents a certified array (November 2017). The stations labelled are the data base for the study which is subject of this paper.

have been certified by the CTBTO and are in permanent operation. Another three stations are being under construction and eight sites are still in the process of planning (CTBTO Preparatory Commission, 2017b). Meanwhile, the detection capability of the network was demonstrated based on natural sources of infrasound, e.g. the Chelyabinsk meteorite over Russia in 2013 (Le Pichon et al., 2013; Pilger et al., 2015).

Each IMS infrasound station is constructed as an array consisting of at least four sensors, i.e. microbarometers with a sensitivity down to $1 \mathrm{mPa}$. To enhance a station's detection capability in a noisy environment, arrays are equipped with acoustic filters providing additional noise reduction at each sensor (Hedlin et al., 2003; Alcoverro and Le Pichon, 2005). Altogether, each array serves as acoustic antenna that gives indication of azimuth direction and apparent wave velocity of a passing signal. In addition to differential pressure, the majority of stations are equipped with MB2000 and MB2005 microbarometer sensors which also record absolute air pressure at a sampling rate of $1 \mathrm{~Hz}$ (Ponceau and Bosca, 2010). This channel allows for measuring fluctuations with frequencies ranging from DC to $40 \mathrm{~Hz}$, encompassing atmospheric dynamics of different scales. The differential pressure channel operates at a bandwidth of 0.01 to $27 \mathrm{~Hz}$ (MARTEC, 2006). Sensor electronic noise amounts to $2 \mathrm{mPa}$ $\left(2 \times 10^{-5} \mathrm{hPa}\right)$, which is negligibly small in terms of atmospheric dynamics relevant in this study.

Compared to about 11000 surface-based stations of the Global Observing System (GOS) of the World Meteorological Organization (WMO), the majority of which are also recording atmospheric pressure (WMO, 2018a), the IMS infrasound network is relatively coarse. Nevertheless, given its accuracy and high temporal resolution, the almost continuous barometric recordings by the IMS infrasound network constitute a unique, global set of data. Although WMO prescribes that its newly implemented barometric sensors fulfil certain requirements, such as $0.1 \mathrm{hPa}$ resolution and an output averaging time of $1 \mathrm{~min}$ (WMO, 2014), reporting intervals actually vary between $1 \mathrm{~min}, 10 \mathrm{~min}, 1 \mathrm{~h}$, and $3 \mathrm{~h}$ within the GOS, depending on the station (WMO, 2018b). The Integrated Surface Database (Smith et al., 2011) provides hourly data of meteorological stations worldwide, including WMO's GOS, which are standardized in terms of quality control and data format.

Besides the high temporal resolution and accuracy of the IMS infrasound station data, its multi-sensor array configurations are a valuable feature when studying atmospheric dynamics. A similar barometric array with four sensors was used by Hauf et al. (1996) for deriving gravity waves from pressure fluctuations. Using the IMS arrays, such analyses can be performed on a global scale.

\section{Data selection and handling}

As previously mentioned, the focus in this study is on geographic variability of atmospheric tides based on absolute pressure recordings. From the 49 infrasound stations certified so far, we have selected 17 sites as data base (labelled triangles in Fig. 1). The selection accounted for various aspects, one of which is data availability. Most of the microbarometers record absolute pressure although the time series cover non-uniform periods. This results from subsequent installation and certification of new sites since the CTBTO initiated the design of the IMS. When selecting the stations, we have also aimed at a uniform geographic distribution of the stations with limited periods of missing data.

The sampling rate of absolute air pressure data is generally $1 \mathrm{~Hz}$. At some stations, recordings of even $20 \mathrm{~Hz}$ are available. Taking into account that significant air pressure changes take several minutes to hours rather than seconds, we have chosen a time step of $1 \mathrm{~min}$ and have therefore reduced the enormous amount of data. As a consequence of very different topographic locations of the infrasound arrays all over the world, e.g. I27DE in Antarctica and I17CI in Côte d'Ivoire, the barometric time series naturally differ from each other. For reasons of comparability and due to the fact that the recorded air pressure is not reduced to mean sea level, we concentrate on air pressure fluctuations around the annual mean. For this purpose, the respective annual mean is subtracted from the annual data sets, resulting in fluctuations around zero.

In case of multiple recordings per array the aforementioned procedure is adapted to each element's time series. Afterwards, as schematically illustrated in Fig. 2, the median of the mean-free recordings is extracted. Overall, we have only one record per station and are able to diminish the problem of temporary missing data at a single sensor.

Nonetheless, the majority of stations only provide one data set of absolute air pressure, corresponding to one sensor. As a consequence, supplementing the occurring errors or miss- 


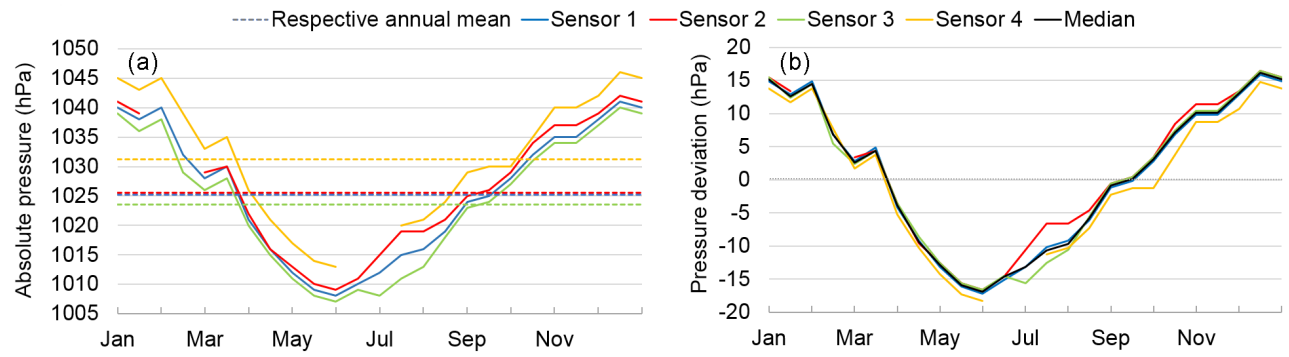

Figure 2. Schematic illustration for handling an annual data set of a four-sensor array. Different pressure at the various sensors (a) can result from the calibration or from different altitudes since the arrays have an aperture of 1-3 km (Evers and Haak, 2010). Here, temporarily missing data for sensors 2 and 4 are without significant consequence when deriving the median (b) as time series for a multi-sensor station.

ing data is beyond the realms of possibility. Therefore, obvious erroneous values are handled as missing data; i.e. values which deviate from the mean by more than 4 times the standard deviation. Such outliers are additionally examined on plausibility (e.g. cyclones). Figure 3 provides an overview on data availability of absolute pressure for the selected stations. The lack of data is related to, among others, station maintenance, power failures caused by various reasons, and erroneous data.

The remaining data sets are up to 13 years long and thus sufficient for analysis in regard to dynamic features as long period phenomena (such as planetary waves), short period phenomena (such as gravity waves), and tides are well represented within this time interval. However, the time interval is likely too short to identify reliable trends, e.g. those associated with climate change. Since our analyses are based on the pressure deviation from the respective annual means, longterm trends are removed anyway. The remaining time series clearly reveal characteristics of their geographic location. As an example, two data sets are shown in Fig. 4, namely those of the midlatitudinal station IS26 (Germany, Fig. 4a) and the tropical station IS21 (Marquesas Islands, French Polynesia, Fig. 4b).

In the tropics at IS21, the annual cycle is characterized by comparatively small amplitude. The absence of large-scale pressure gradients leads to a dominant signature of smallscale phenomena such as thunderstorms, or small-amplitude phenomena such as the solar tides. In the tropics, the semidiurnal tide's amplitude can amount to $1.3 \mathrm{hPa}$ (Dai and Wang, 1999; Hoinka, 2007; Schindelegger and Ray, 2014). Even though this tidal amplitude is only about $0.1 \%$ of the absolute air pressure, its proportion of the annual pressure fluctuation amplitude amounts to about $20 \%$.

However, at IS26 the annual amplitude (about $30 \mathrm{hPa}$ ) masks small-scale amplitudes like those of the atmospheric tides. The negative deviations which predominantly occur in winter are larger than the positive deviations throughout a year. In winter, temperature gradients between equator and North Pole are largest due to differing solar radiation and, thus, energy balance. The compensating processes result in

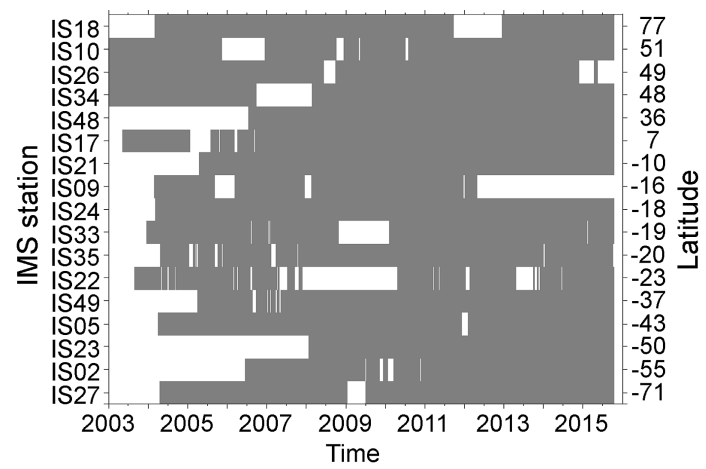

Figure 3. Daily availability of absolute pressure data at the selected IMS stations. White boxes indicate missing data.

stronger westerlies and more intense (low pressure) cyclones than in summer.

\section{The MERRA-2 reanalysis data}

MERRA-2 is NASA's latest atmospheric reanalysis of the modern satellite era provided by the Global Modelling and Assimilation Office (GMAO; Gelaro et al., 2017). Data are available on a $0.625^{\circ} \times 0.5^{\circ}$ grid, beginning in 1980 (Bosilovich et al., 2016). Since ECMWF's ERA-interim provides reanalysis data at the meteorological main times (00:00, 06:00, 12:00, 18:00 UTC) only, interpolation methods would be necessary for detailed studies of tides with periods shorter than $24 \mathrm{~h}$ (Ray and Ponte, 2003). MERRA-2 has the benefit of providing data at an interval of $3 \mathrm{~h}$ either as instantaneous or as time-averaged fields (Bosilovich et al., 2016). For this study we retrieved the $3 \mathrm{~h}$ time-averaged surface pressure field (GMAO, 2015). Data have been interpolated at the locations of the 17 IMS stations defined in Sect. 3. Analogous to Fig. 4, MERRA-2 time series for IS26 and IS21 are shown in Fig. A1.

To analyse the tidal effects at various IMS infrasound stations and to derive other features related to atmospheric dynamics from the pressure fluctuations, e.g. planetary waves, 

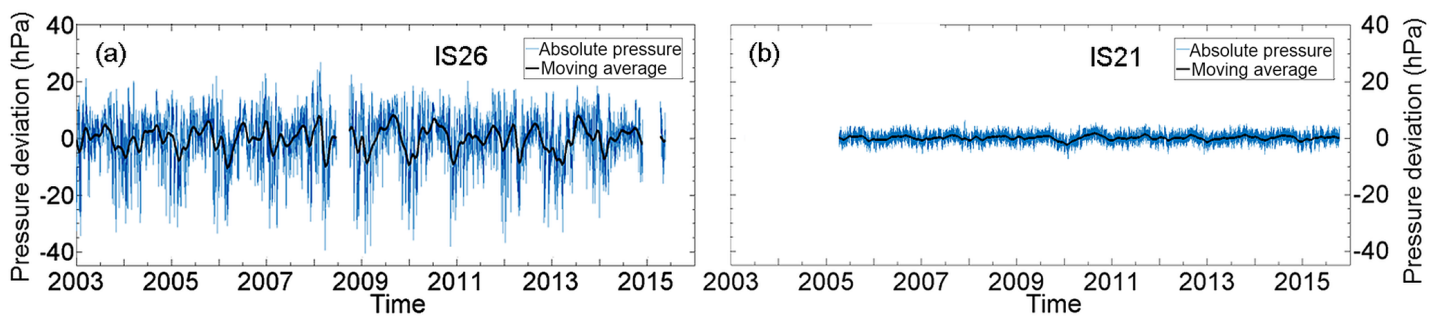

Figure 4. Absolute pressure data recordings of the IMS infrasound stations IS26 (a) and IS21 (b) as deviations from the annual means. The moving average highlights the superordinate annual variation.
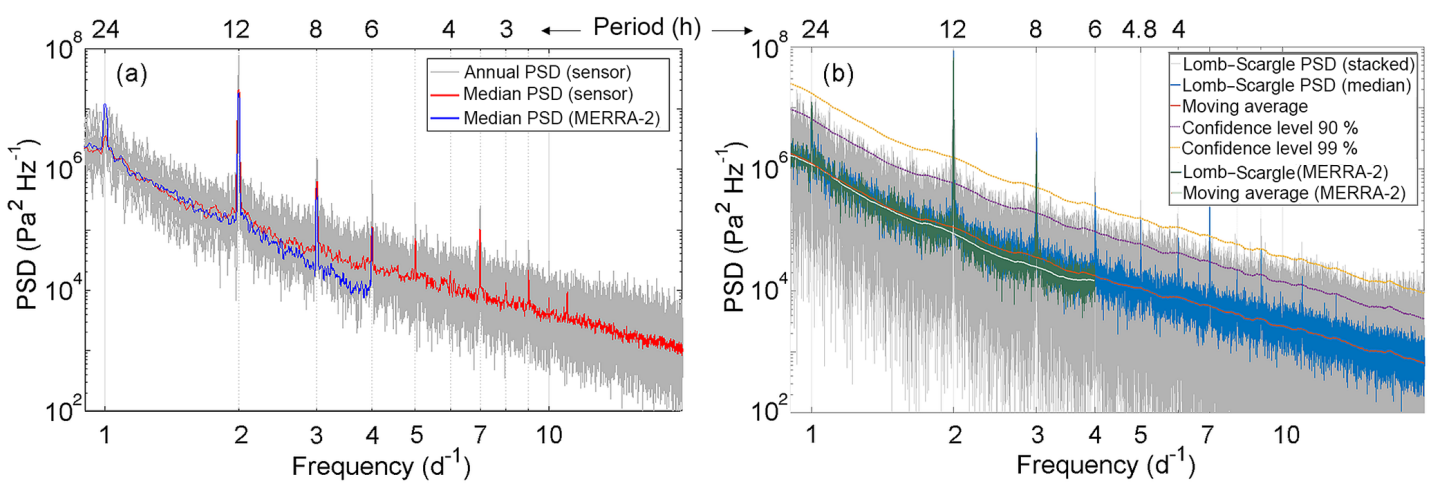

Figure 5. PSD plots for IS26. (a) The red curve depicts the median PSD for the entire period from 2003 to 2015 as derived from the barometric sensor. Each of the grey PSD curves belongs to a single year within this period. Panel (b) shows the Lomb-Scargle PSD spectrum based on the entire time series. In both panels, the solar tides appear as sharp peaks. The MERRA-2 reanalysis reveals a higher PSD for the diurnal tide.

we apply various spectral analysis methods on both the IMS barometric data and the MERRA-2 data.

\section{Spectral analysis tools}

Fourier methods' outputs comprise, inter alia, wavelets and the power spectral density (PSD) of the time series. Computing the PSD of a time series helps to provide a first impression of the data set. In contrast to Marty et al. (2010), who applied the PSD on intervals of 12 days, we have chosen time windows of 6 months. Consequently, single days missing do not significantly affect the analysis. When considerable data gaps exist in the time series (cf. Fig. 3), the PSD calculation is rejected for the particular year. An example of a PSD is given in Fig. 5a, based on the pressure fluctuation at IS26 from 2003 to 2015. A combined PSD plot for all stations selected is provided in Sect. 6. Additionally, the PSD is calculated based on the Lomb-Scargle algorithm which is capable of handling missing data without reducing the data basis (Lomb, 1976; Scargle, 1982). An example is given in Fig. 5b. A confidence level is added to the Lomb-Scargle PSD spectrum for classifying the peaks' significance. The Lomb-Scargle PSD of the MERRA-2 time series is in good agreement.
Another useful and often used tool for geophysical studies is to compute a wavelet analysis (Daubechies, 1992). In our study it is based on the Morlet wavelet function. The barometric time series can be analysed in the time-frequency space, enabling the determination of both the dominant frequencies and their temporal variation (Torrence and Campo, 1998). Figure 6 includes the wavelet power spectrum for station IS26. As the diurnal tide is not very prominent at IS26 (cf. Fig. 5), it is hidden in synoptic pressure fluctuations rather than being represented by a distinct line. The semidiurnal tide is however recognizable by a bright horizontal line. The wavelet power spectrum does not provide detailed information on smaller period scales or even seasonal variations within the diurnal period range.

\section{Results and discussion}

In this section, we highlight and discuss the findings on several dynamic features of the barometric data considered. The focus is on geographic and temporal variability of the solar atmospheric tides. 


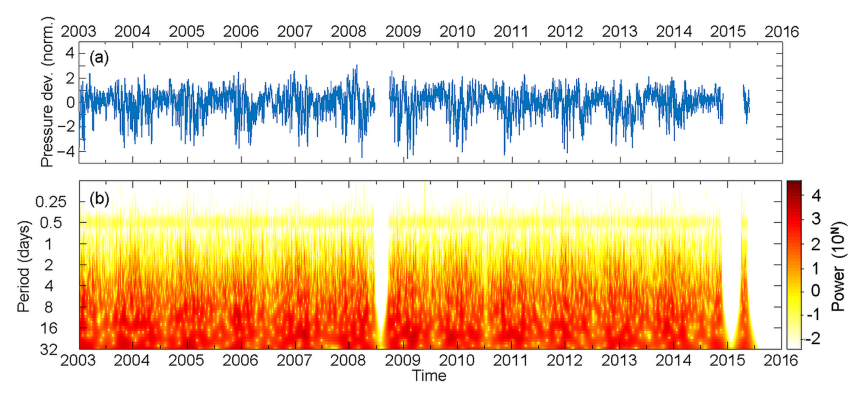

Figure 6. Wavelet analysis for station IS26 from 2003 to 2015 . The time series in panel (a) corresponds to Fig. 4a but is normalized by its standard deviation, which amounts to $8.78 \mathrm{hPa}$. The resulting power spectrum (b) is colour-coded. The ordinate axis represents the Fourier period in days.

\subsection{Geographic variability of the dynamic features}

The PSD curves of the selected data sets reveal both consistent and differing features like those shown for IS26 (Fig. 5a). For reasons of comparability the median PSD curves are colour-coded and sorted according to the stations' latitude in Fig. 7. For MERRA-2 data this PSD spectrum is given in Fig. A2.

\subsubsection{Phenomena in the period scale exceeding 1 day}

In general, the PSD increases with decreasing frequency. Over periods exceeding 1 day, tropical stations can be clearly distinguished as the PSD values are significantly lower than at latitudes beyond $\pm 30^{\circ}$. The difference is in the order of one to the power of 10. In the midlatitudes and high-latitudes extratropical cyclones and planetary waves lead to larger pressure fluctuations compared to the tropics, where air pressure fluctuations are relatively small throughout a year, as was shown in Fig. 4b. In Fig. 6, the wavelet spectrum provides extended information on planetary wave scales (periods up to 32 days). These are strongest in the winter months when temperature gradients between equator and North Pole are largest.

\subsubsection{The solar tides}

Geographic differences between the tidal effects on air pressure may be worth discussing in the context of previous studies on atmospheric tides derived from barometric data. In Fig. 7, tidal peaks clearly appear with up to $9 \mathrm{cpd}$. The most striking peak, in terms of a constantly high PSD, is the semidiurnal tide (12 h). In addition, 3 and $4 \mathrm{cpd}$, which are called terdiurnal $(8 \mathrm{~h})$ and quarterdiurnal tide $(6 \mathrm{~h})$, respectively, can be recognized at the majority of stations. Generally speaking, several tidal modes are dominant throughout the entire hemispheres, starting with a period of $24 \mathrm{~h}$ which is known as the solar diurnal tide.

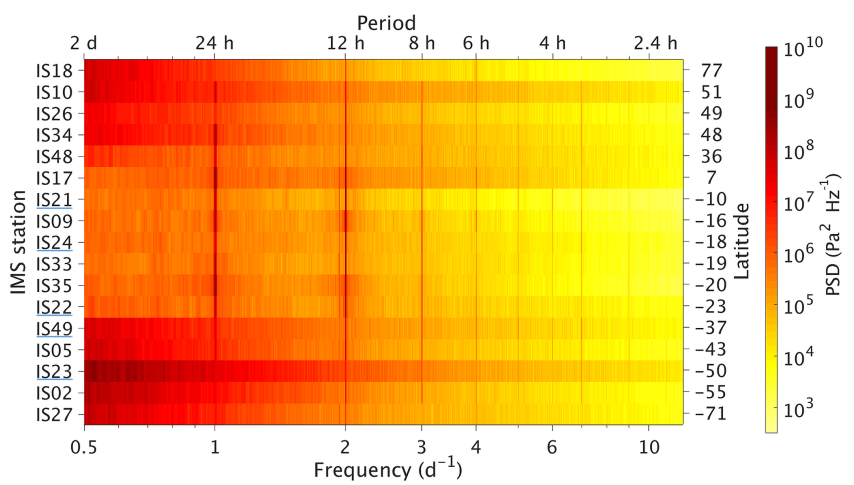

Figure 7. Median PSD of the selected data sets. The IMS infrasound stations are sorted from north (top) to south (bottom) with the latitudes indicated on the right axis. Stations on (small) islands are underlined. The darker the colour the higher is the PSD. The corresponding spectrum for MERRA-2 data can be found in Fig. A2.

According to findings on global pressure oscillations by Haurwitz (1965), whose study was based on more than 200 irregularly distributed stations, the diurnal tide's amplitude decreases with increasing latitude, following the latitudinal decrease of solar insolation. By using the IMS infrasound stations and by considering the picture provided in Fig. 7, we come to a similar conclusion: the PSD and thus the amplitudes are at a maximum in the low-latitudes and almost disappear at the high-latitude stations IS18 and IS27. The PSD, however, does not steadily decrease towards the polar regions. For example, IS34 and IS10 are characterized by relatively large PSD values which can be explained by the continental location of the sensors: in summer, the rapid warming of the landmasses causes a stronger diurnal effect. Even within the tropics, the PSD values differ markedly since the amplitude of the diurnal tide strongly depends on local surface conditions (Haurwitz, 1965), e.g. over the ocean it is weaker than over landmasses (Dai and Wang, 1999). For example, the PSD is comparatively weak at maritime stations like IS21, IS24, and IS22. The midlatitudinal stations in the Southern Hemisphere are in the majority located on islands or otherwise close to an ocean. Hence, the corresponding PSD values are generally weaker than in the Northern Hemisphere. Dai and Wang (1999) also emphasized a strong diurnal tide over high terrain which might contribute to the prominent PSD signal at IS34 in Mongolia as well. Extracting the tidal components from the PSD spectrum shows that the diurnal oscillation is not the strongest tide. Haurwitz (1965) even claimed that the amplitude of the semi-diurnal tide was "generally considerably larger than that of the diurnal oscillation". Regarding tropical stations, this agrees with Fig. 8, in which the means of monthly amplitudes of the tidal components are given for each station. The amplitude means of the semi-diurnal tide are much larger than the diurnal ones for most stations, in particular at the low latitude stations; hence, the $12 \mathrm{~h}$ oscillation can often be eas- 


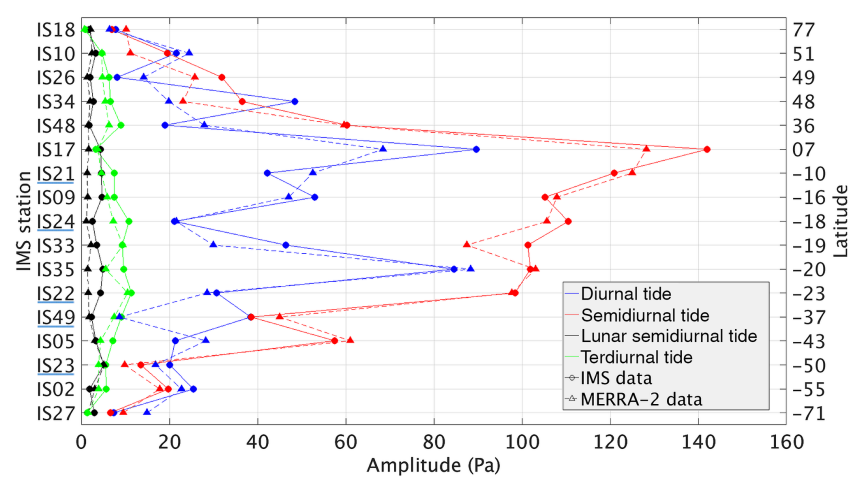

Figure 8. Comparison of the mean tidal amplitudes as calculated from the IMS sensors' time series and MERRA-2 reanalysis. The mean amplitudes of the solar tides are in good agreement. The increased amplitude of the lunar tide at IS23 can be seen as misrepresentation since it matches the MERRA-2 data in which the lunar tides are not represented (Fig. A2) as in Fig. 7.

ily recognized in barometric recordings at tropical stations (e.g. Oberheide et al., 2015) where large-scale pressure oscillations do not exist (see Figs. 4b and A3). The pressure maxima occur at approximately 10:00 and 22:00 Local Solar Time (Haurwitz, 1956; Dai and Wang, 1999; Marty et al., 2010) or, more precisely, "about $2.3 \mathrm{~h}$ before solar noon and solar midnight" (Whiteman and Bian, 1996).

At high latitude stations, however, the diurnal tide's amplitude is larger than the semi-diurnal component. The semidiurnal tide is driven, amongst other origins, by the absorption of solar radiation by water vapour (Whiteman and Bian, 1996). Both the concentration of water vapour and the insolation are highest in the tropics, thus the maxima can consequently be found in the low latitudes where the effect of the diurnal tide is exceeded, e.g. the amplitude mean found for IS17 amounts to $1.4 \mathrm{hPa}$ (diurnal tide: $1 \mathrm{hPa}$ ).

The amplitude means of the terdiurnal tide are less by about one power of 10 at tropical stations. Amplitude maxima can be found in the tropics (IS22: 13 Pa) and minima at high latitudes where the amplitude is less than $2 \mathrm{~Pa}$. Spectral analyses of MERRA-2 time series resulted in slightly lower estimates of the terdiurnal tide. These can be traced back to the $3 \mathrm{~h}$ sampling of reanalysis data which might be too sparse for exact estimates of the $8 \mathrm{~h}$ cycle.

The generally good agreement with amplitude means calculated from MERRA-2 time series underlines the IMS infrasound network's capability for studying geographical variations of atmospheric dynamics such as solar tides or gravity waves. Vice versa, our findings imply that the solar tides' representation in MERRA-2 is accurate.

\subsubsection{The lunar tides}

The most striking PSD peaks in Fig. 7 are clearly related to the solar day. Besides, the individual PSD curves of some
IMS stations reveal a secondary semi-diurnal peak. It can also be recognized in Fig. 7 for a couple of equatorial stations but not in the equivalent MERRA-2 analysis (Fig. A2). The period is $12 \mathrm{~h}$ and $25 \mathrm{~min}$ and thus exactly half a lunar day. It is striking that at IS27 the lunar tide seems even more prominent than the diurnal solar tide. Other significant peaks are generally found at tropical stations such as IS17 and IS21. Figure 9 shows the Lomb-Scargle PSD spectra of IS27 and IS21, both showing a highly significant peak next to the main (solar) semi-diurnal peak. The peak is not matched by MERRA-2. The monthly mean amplitude of the semidiurnal oscillation related to the lunar day given in Fig. 8 is very small in relation to the solar tides.

A study of Chapman and Westfold (1956) indicated that the global distribution of the lunar semi-diurnal tide is similar to that of the solar counterpart. Hence, the mean annual amplitude is maximum in equatorial regions and decreases with increasing latitude (Haurwitz and Cowley, 1969; Schindelegger and Dobslaw, 2016). Combined with its generally small amplitude (Lindzen and Chapman, 1969), this explains why distinct signatures of the lunar semi-diurnal tide (Fig. 7) are mainly concentrated on tropical stations in our study. In this context, the evidence of a tidal peak related to the lunar day at the Antarctic station IS27 is even more surprising. However, the monthly amplitude mean we found at IS27 is only $3 \mathrm{~Pa}$. For MERRA-2 data we calculated a mean amplitude of $2 \mathrm{~Pa}$, although the lunar tide does not seem represented (see Figs. 9a and A2). The significant PSD peak still raises the question about the excitation mechanism of the tidal signal since the dynamic effect of the gravitational pull of the Moon seems to be too low in the Antarctic region. As IS27 is mounted on the Ekstroem Ice Shelf, the ocean tide may affect barometric recordings to a small but considerable extent by vertically lifting the sensor.

Vertical sensor lifting can be induced by the body tide, the ocean tide itself, and ocean tide loading effects. Near IS27, these excitations amount to about $4 \mathrm{~Pa}$ (Schindelegger and Dobslaw, 2016). The open-ocean tide amounts to $0.5 \mathrm{~m}$ (Kohyama and Wallace, 2014). To a certain extent, the Ekstroem Ice Shelf moves with the ocean tide which may enhance the barometric effect of the lunar tide as the vertical movement translates into a barometric signal.

\subsection{Seasonal variability of the solar tides}

Focusing on the solar tides again, the monthly PSD is computed to derive the seasonal variability of the diurnal, semidiurnal and terdiurnal tide. For the period range between $3 \mathrm{~h}$ and 5 days the monthly PSD is shown for station IS21 in Fig. 10a. Several tidal harmonics are highlighted by distinct horizontal lines. At first sight, the semi-diurnal oscillation is widely of continuous power. To specify the seasonal characteristics, the variances of the most dominant tides are given in Fig. 10b. It turns out that the semi-diurnal tide's power is not that uniform throughout a year but mostly exhibits 


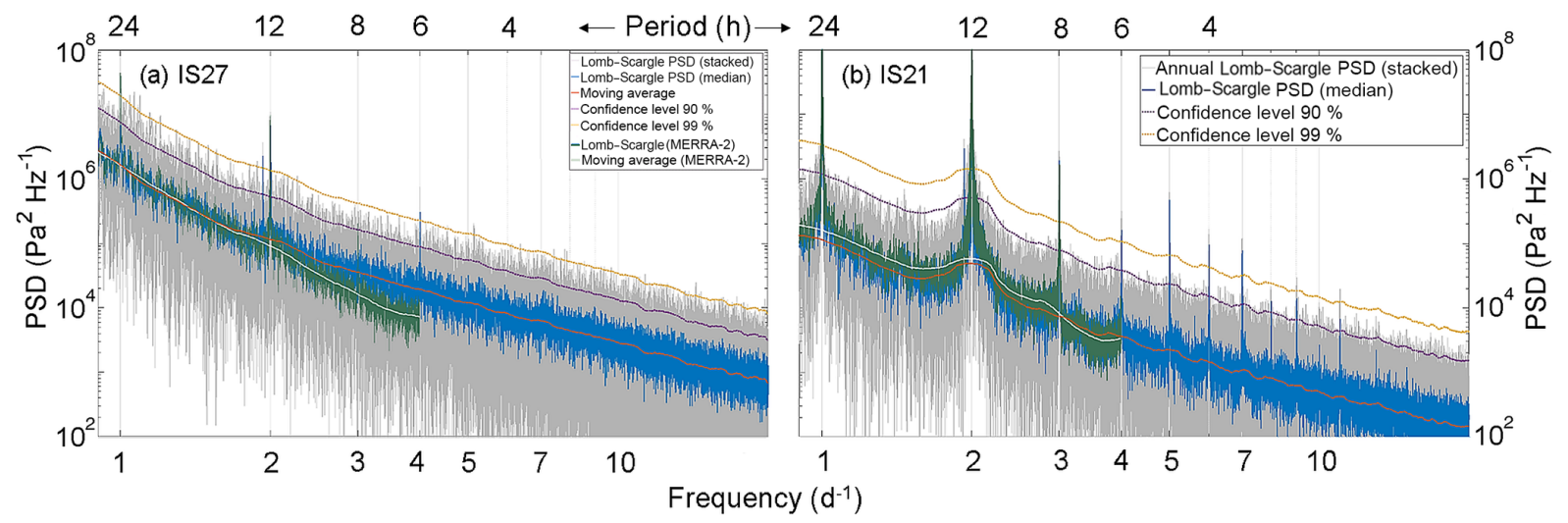

Figure 9. Lomb-Scargle PSD curves for (a) IS27 (Antarctica) and (b) IS21 (Marquesas Islands). The peaks closely left of the predominant semi-diurnal peak are related to the lunar day. This peak is not present in MERRA-2 reanalysis.

two maxima. They predominantly occur in the equinoctial months, which is in line with studies by Hann (1918) and by Haurwitz and Cowley (1973). The diurnal tide's variance is generally smaller than the semi-diurnal tide's variance. The maxima seem to occur without a clear periodic cycle. The terdiurnal tide maximizes twice per year. Besides its absolute annual maximum in winter, a secondary maximum with less power can be detected in summer. Ray and Poulose (2005) evidenced this seasonal variation of the terdiurnal tide for barometric recordings in the United States. We can now validate it for the IMS infrasound stations distributed all over the world. The variation of the monthly mean amplitudes (not shown) of both MERRA-2 and IMS data is in line with this annual cycle.

In Fig. 11, the occurrence months of the absolute variance's maxima between 2003 and 2015 are depicted (one maximum each year). A month's rectangle is highlighted in the colour of the respective tidal harmonic if in at least three years (i.e. approximately $25 \%$ ) the variance's annual maximum was detected within this month. This enables the detection of seasonal patterns for each of the tides.

The annual maximum of the terdiurnal tide (green) is, on average, detected during the winter months. A second, smaller maximum can be detected in the summer months as it has been validated for IS21 in Fig. 10 (Ray and Poulouse, 2005). An exception is given by the equatorial station IS17 at which the terdiurnal tide's power is relatively constant throughout a year. Besides a small maximum in December or January, the occurrence of another small maximum ranges between March and July, depending on the year considered.

The annual cycle of the semi-diurnal tide (red) exhibits two maxima during the equinoxes with only a small difference in power (Hann, 1918; Haurwitz and Cowley, 1973). The absolute maximum predominantly occurs during the spring equinox. The semiannual cycle showing maxima around the equinoxes was also found in ECMWF reanalysis after interpolation of the $6 \mathrm{~h}$ fields (Van den Dool et

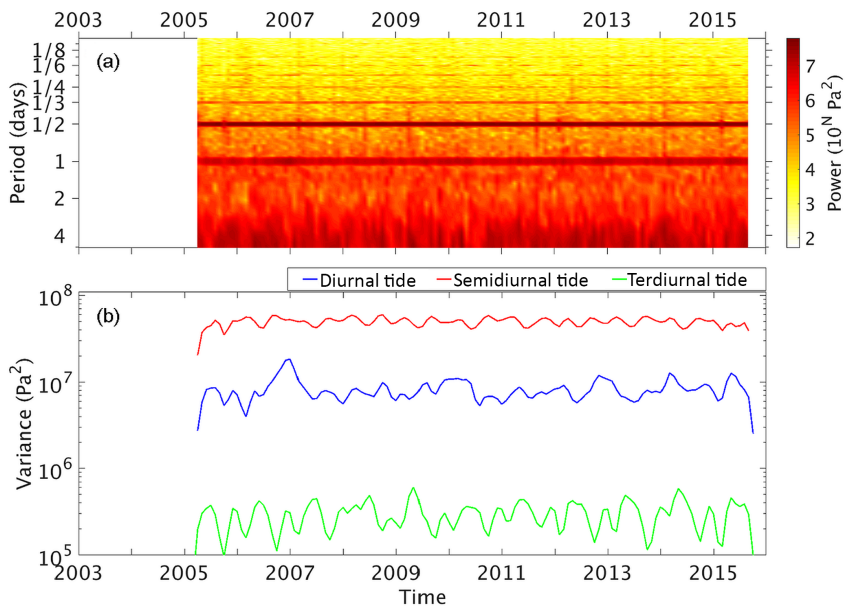

Figure 10. Colour-coded PSD spectrum (a) of the monthly air pressure fluctuations at IS21 as function of time and Fourier period, and the variances of the diurnal, semi-diurnal, and terdiurnal tide (b).

al., 1997; Díaz-Argandona et al., 2016). Exceptions are the high-latitudinal stations: At IS18 the maxima are detected in northern winter, whereas at IS27 the maxima of the semidiurnal tide are distributed over several months. Because of the low tidal amplitude in high latitudes, variances in the tidal period ranges are certainly affected by noise.

As one can also recognize from Fig. 11, the annual variation of the diurnal tide (blue) is not indicated by such a clear pattern as with the aforementioned tides. The maxima would be expected in summer when solar radiation leads to increased heating of land masses (Haurwitz and Cowley, 1973; Dai and Wang, 1999). In the midlatitudes also a semiannual cycle is known from observations (Hann, 1918), but the absolute maximum was primarily found in (early) summer. This is also a finding in our observations which agrees with the MERRA-2 time series analysed. However, the annual cycle of the diurnal tide strongly depends on the ge- 


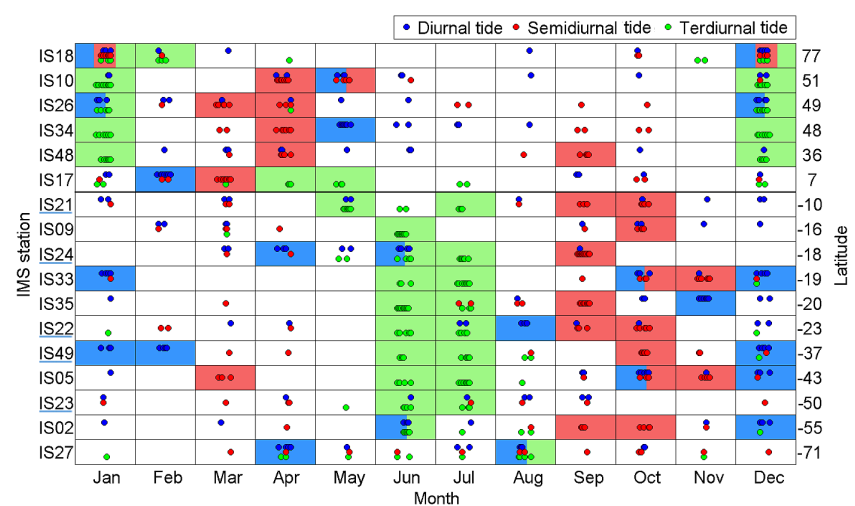

Figure 11. Detection times of the primary annual maxima of the tides' variances between 2003 and 2015. The thicker black line depicts the transition from northern to southern latitudes. For the IMS infrasound station indicated on the left axis, each dot marks the month in which the absolute maximum of each year appeared between 2003 and 2015. The offsets between the dots serve for the purpose of distinguishability. By highlighting accumulations of annual maxima, seasonal patterns and its differences between the Northern Hemisphere and the Southern Hemisphere become apparent.

ographic location of the station. At maritime stations, e.g. those on oceanic islands such as IS21 (Marquesas Islands) or IS22 (New Caledonia), the annual variation of the diurnal tide is small, resulting in a varying appearance of the annual maximum or even no explicit one. Contrarily, at IS34 in Mongolia the maxima of the diurnal tide are always in the summer season when the Asian continent is dominated by warm air masses. In winter, when the high-pressure system with the cold air mass prevails, the diurnal tide is less powerful. At other stations in the midlatitudes and high-latitudes, the low-amplitude diurnal tide is often hidden in the noise or masked by synoptic pressure gradients. In particular, this regards the stations IS02, IS10, IS18, IS23, IS26, and IS27. Therefore, the seasonal variation found here is not that clear as it would be expected from the theory of excitation by insolation (e.g. Dai and Wang, 1999). Instead of an annual cycle exhibiting one maximum in summer (Haurwitz and Cowley, 1973), maxima can partly be found in winter (Fig. 11) since the largest pressure gradients are present in those months.

\section{Conclusions}

Based on absolute pressure data of the global IMS infrasound network we have compared signatures of the atmospheric tides, derived by using spectral analysis tools, with surface pressure reanalysis from MERRA-2. We intended to show the capability of this network for future applications on temporal and geographic variability studies of atmospheric dynamics and assumed to focus on the thermally forced tides by the Sun. These generally appear much stronger in atmo- spheric recordings than gravitationally induced tides (Chapman and Lindzen, 1970). The sensors of the IMS infrasound network are also capable of representing the gravitationally forced lunar tide.

We have detected the lunar semi-diurnal tide at almost all IMS stations despite its small amplitude (Lindzen and Chapman, 1969). Its PSD peak is highly significant at all tropical stations. The distinctness of this signature in the lowlatitudes is certainly also a result of the accurate sensitivity of barometric sensors at the IMS infrasound stations. Following the review on atmospheric tides by Lindzen and Chapman (1969), the availability of hourly and even shorter term data also proves as a large benefit. This is underlined by the fact that the existence of the lunar tide could not be proved in MERRA-2 time series. In contrast, we have found a significant lunar semi-diurnal tide at the Antarctic IMS station far beyond the tropics. We have pointed out that it can be of spurious nature as indirect sensor lifting effect of the ocean tide (Schindelegger and Dobslaw, 2016).

Our spectral analyses have shown that quantitative measures of the diurnal, semi-diurnal, and terdiurnal tides, e.g. PSD and amplitude, are well represented by both IMS recordings and MERRA-2 data. Despite the different sampling intervals of $1 \mathrm{~s}$ (IMS) and $3 \mathrm{~h}$ (MERRA-2), only slight differences were found which can be related to the spatial resolution of the reanalysis field and local effects at the IMS stations. Our global observation regarding the diurnal and semi-diurnal solar tide is widely compliant with previous studies which were based on observations and model analysis. The IMS infrasound network is smaller than previous networks (e.g. Haurwitz, 1965; Dai and Wang, 1999) but it is equipped with highly accurate barometric sensors which are uniformly distributed over the globe. In future, gravity waves which are in the period range within 1 day could be examined given the accuracy and high temporal resolution of the barometric data from the IMS infrasound network.

Data assimilation in existing empirical models of both solar (e.g. Dai and Wang, 1999; Schindelegger and Ray, 2014) and lunar tides (e.g. Kohyama and Wallace, 2014; Schindelegger and Dobslaw, 2016) at ground level would be a valuable application of the IMS infrasound data. By now, the focus of such empirical models is often limited to the diurnal and the semi-diurnal tide. The accurate barometric IMS data sets also allow for analysing the global characteristics of higher tidal harmonics. For this purpose, the set of selected IMS infrasound stations is still extendable. So far, the 13 years of data availability have revealed valuable findings on the seasonal variation of the terdiurnal tide as well. Other tidal harmonics and their excitation sources could be studied since up to $9 \mathrm{cpd}$ clearly appear in the PSD analysis of our data set. For example, the quarterdiurnal tide has been investigated in few studies only. The one by Pramanik (1926) was just based on continental stations. By using the IMS infrasound network also maritime regions can be represented by using stations located on islands. 
We have studied the terdiurnal tide with a period of $8 \mathrm{~h}$ by using barometric recordings. To our knowledge, this has only been performed on a more regional scale so far, e.g. in the United States (Ray and Poulose, 2005), or as a collection of data in absence of a uniform network (Hann, 1918). On a global scale, we have clearly identified a semiannual cycle of the terdiurnal tide with maxima in summer and winter. The excitation mechanism of the terdiurnal tide must be different or more diverse compared to the diurnal and semidiurnal tide, respectively. Wave-wave interactions are considered to be at least a secondary source of atmospheric tides (e.g. Forbes and Wu, 2006; Moudden and Forbes, 2013). As a next step, using the IMS infrasound network for temporal correlation between the tidal harmonics and other dynamics such as planetary waves or gravity waves could lead to clarification regarding such interactions. This is significant in the context of ARISE2 and for other communities with the objective of achieving an enhanced understanding of dynamic processes in the atmosphere; e.g. in the context of the future verification of the CTBT, improved atmospheric models are needed for assessing the IMS infrasound network performance in higher resolution, leading to advanced source characterisation and location.

Data availability. MERRA-2 data can be accessed online through the NASA Goddard Earth Sciences Data Information Services Centre (GES DISC). The surface pressure reanalysis data used in this study can be retrieved from the Assimilated Meteorological Fields (GMAO, 2015). Access to the IMS network's data such as barometric recordings of the infrasound stations can be provided by the respective National Data Centres of the CTBTO. 


\section{Appendix A}
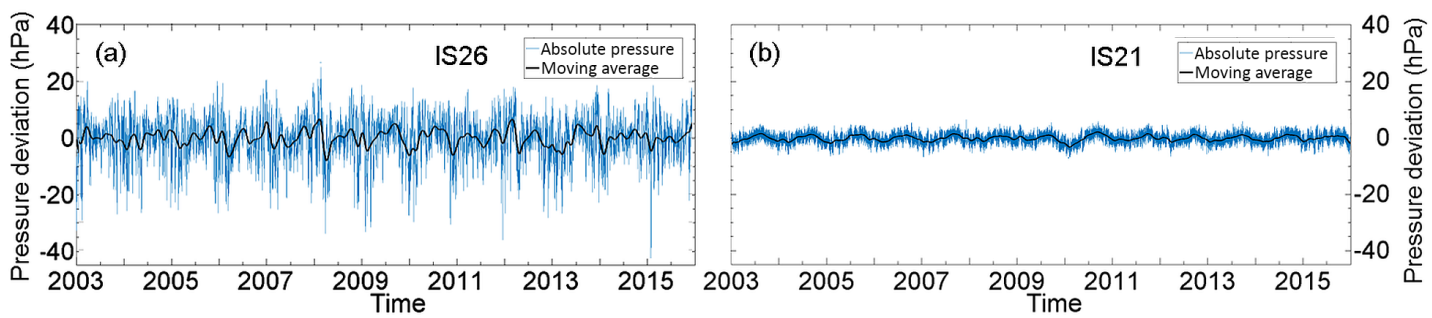

Figure A1. Absolute surface pressure data of MERRA-2 at IMS stations IS26 (a) and IS21 (b) as deviations from the annual means. The moving average highlights the superordinate annual variation. See also Fig. 4.

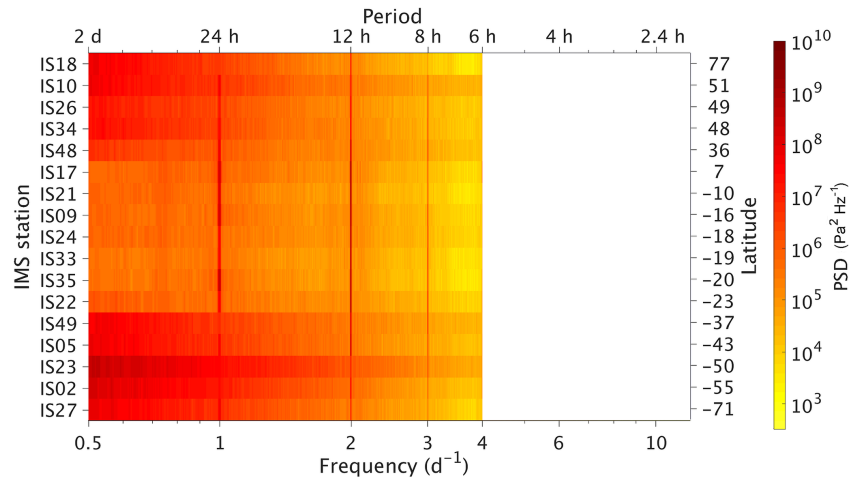

Figure A2. Median PSD spectrum of the MERRA-2 time series (analogue to Fig. 7). The period range is limited at $6 \mathrm{~h}$ due to the sampling interval of MERRA-2 data (3h). The colour bar is slightly different from Fig. 7. The lunar semi-diurnal tide is not represented in MERRA-2 data.

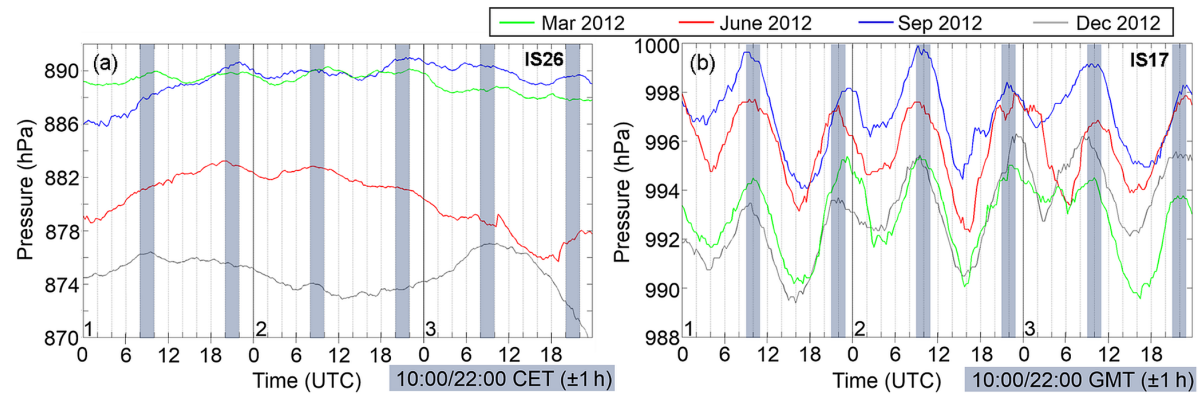

Figure A3. Absolute pressure on three days of different seasons at (a) IS26 (UTC+01) and (b) IS17 (UTC+00). The semi-diurnal tide can clearly be detected by the naked eye at the tropical station IS17, whereas at IS26 synoptic pressure variations mask the reduced tidal effect in the mid-latitudes. The grey columns indicate the expected times of the semi-diurnal tides' pressure maxima (e.g. Haurwitz, 1956). Note that these barometric recordings are exemplarily shown for 2012 and are not necessarily representative for any of the four seasons. 
Author contributions. PH prepared and revised the manuscript and performed the data analyses with support from LC and CP. LC supervised the project. All authors discussed the results and thereby contributed to the final version of the manuscript.

Competing interests. The authors declare that they have no conflict of interest.

Disclaimer. The views expressed herein are those of the authors and do not necessarily reflect the views of the CTBTO Preparatory Commission.

Acknowledgements. The research leading to these results has been performed within the ARISE2 project (http://ARISE-project.eu, last access: 3 April 2018) at BGR (Federal Institute for Geosciences and Natural Resources) as the German National Data Centre of the CTBTO. The ARISE2 project received funding from the European Commission's Horizon 2020 program under grant agreement 653980. The authors thank their BGR colleague Ole Ross for his technical assistance with MERRA-2 data retrieval. We also thank the two anonymous reviewers for their helpful comments and constructive remarks.

Edited by: Gerd Baumgarten

Reviewed by: two anonymous referees

\section{References}

Alcoverro, B. and Le Pichon, A.: Design and optimization of a noise reduction system for infrasonic measurements using elements with low acoustic impedance, J. Acoust. Soc. Am., 117, 1717-1727, https://doi.org/10.1121/1.1804966, 2005.

Assink, J. D., Waxler, R., and Drob, D.: On the sensitivity of infrasonic traveltimes in the equatorial region to the atmospheric tides, J. Geophys. Res.-Atmos., 117, D01110, https://doi.org/10.1029/2011JD016107, 2012.

Baldwin, M. P. and Dunkerton, T. J.: Stratospheric harbingers of anomalous weather regimes, Science, 294, 581-584, https://doi.org/10.1126/science.1063315, 2001.

Blanc, E., Le Pichon, A., Ceranna, L., Farges, T., Marty, J., and Herry, P.: Global Scale Monitoring of Acoustic and Gravity Waves for the Study of the Atmospheric Dynamics, in: Infrasound Monitoring for Atmospheric Studies, edited by: Le Pichon, A., Blanc, E., Hauchecorne, A., Springer, Dordrecht, the Netherlands, 647-664, https://doi.org/10.1007/978-1-40209508-5_21, 2010.

Blanc, E., Ceranna, L., Hauchecorne, A., Charlton-Perez, A., Marchetti, E., Evers, L. G., Kvaerna, T., Lastovicka, J., Eliasson, L., Crosby, N. B., Blanc-Benon, P., Le Pichon, A., Brachet, N., Pilger, C., Keckhut, P., Assink, J., Smets, P. S. M., Lee, C. F., Kero, J., Sindelarova, T., Kämpfer, N., Rüfenacht, R., Farges, T., Millet, C., Näsholm, S. P., Gibbons, S. J., Espy, P. J., Hibbins, R. E., Heinrich, P., Ripepe, M., Khaykin, S., Mze, N., and Chum, J.: Toward an Improved Representation of Middle Atmospheric Dy- namics Thanks to the ARISE Project, Surv. Geophys., 38, 1-55, https://doi.org/10.1007/s10712-017-9444-0, 2017.

Bosilovich, M. G., Lucchesi, R., and Suarez, M.: MERRA-2: File Specification, Office Note No. 9 (V1.1), GMAO, Greenbelt, MD, USA, 73 pp., 2016.

Braathen, G.: ARISE: A European research infrastructure combining three measurement techniques, WMO Bull., 62, 27-31, 2013.

Butler, S. T. and Small, K. A.: The Excitation of Atmospheric Oscillations, Proc. R. Soc. Lon. Ser.-A, 274, 91-121, https://doi.org/10.1098/rspa.1963.0116, 1963.

Chapman, S. and Lindzen, R. S.: Atmospheric Tides, D. Reidel Press, Dordrecht, the Netherlands, 229 pp., 1970.

Chapman, S. and Westfold, K. C.: A comparison of the annual mean solar and lunar atmospheric tides in barometric pressure, as regards their worldwide distribution of amplitude and phase, J. Atmos. Terr. Phys., 8, 1-23, https://doi.org/10.1016/00219169(56)90087-3, 1956.

Christie, D. R. and Campus, P.: The IMS Infrasound Network: Design and Establishment of Infrasound Stations, in: Infrasound Monitoring for Atmospheric Studies, edited by: Le Pichon, A., Blanc, E., Hauchecorne, A., Springer, Dordrecht, the Netherlands, 29-75, https://doi.org/10.1007/978-1-4020-95085_2, 2010 .

CTBTO Preparatory Commission: 1996: CTBT: A Long-Sought Success, available at: https://www.ctbto.org/the-treaty/, last access: 23 November 2017a.

CTBTO Preparatory Commission: International Monitoring System Infrasound, available at: https://www.ctbto.org/map, last access: 5 December 2017 b.

Dai, A. and Wang, J: Diurnal and Semidiurnal Tides in Global Surface Pressure Fields, J. Atmos. Sci., $\quad 56, \quad 3874-3891, \quad$ https://doi.org/10.1175/15200469(1999)056<3874:DASTIG>2.0.CO;2, 1999.

Daubechies, I.: Ten Lectures on Wavelets, in: CBMS-NSF Regional Conf. Series in Appl. Math. 61, Soc. for Industr. and Appl. Math., Philadelphia, PA, June 1990, 369 pp., https://doi.org/10.1137/1.9781611970104, 1992.

Díaz-Argandona, J., Ezcurra, A., Sáenz, J., Ibarra-Berastegi, G., and Errasti, I.: Climatology and temporal evolution of the atmospheric semidiurnal tide in present-day reanalysis, J. Geophys. Res.-Atmos., 121, 4614-4626, https://doi.org/10.1002/2015JD024513, 2016.

Donn, W. L. and Rind, D.: Microbaroms and the Temperature and Wind of the Upper Atmosphere, J. Atmos. Sci., 29, 156-172, https://doi.org/10.1175/15200469(1972)029<0156:MATTAW>2.0.CO;2, 1972.

Drob, D. P., Picone, J. M., and Garcés, M.: Global morphology of infrasound propagation, J. Geophys. Res., 108, 4680, https://doi.org/10.1029/2002JD003307, 2003.

Evers, L. G. and Haak, H. W.: The Characteristics of Infrasound, its Propagation and Some Early History, in: Infrasound Monitoring for Atmospheric Studies, edited by: Le Pichon, A., Blanc, E., Hauchecorne, A., Springer, Dordrecht, the Netherlands, 3-27, https://doi.org/10.1007/978-1-4020-9508-5_1, 2010.

Forbes, J. M.: Middle-atmosphere tides: recent advances in theory and observation, Adv. Space Res., 4, 87-96, https://doi.org/10.1016/0273-1177(84)90268-0, 1984. 
Forbes, J. M.: Atmospheric tides between $80 \mathrm{~km}$ and $120 \mathrm{~km}$, Adv. Space Res., 10, 127-140, https://doi.org/10.1016/02731177(90)90392-D, 1990.

Forbes, J. M. and Garrett, H. B.: Solar Tidal Wind Structures and the E-Region Dynamo, J. Geomagn. Geoelectr., 31, 173-182, https://doi.org/10.5636/jgg.31.173, 1979.

Forbes, J. M. and Gillette, D. F.: A Compendium of Theoretical Atmospheric Tidal Structures, Part I: Model Description and Explicit Structures Due to Realistic Thermal and Gravitational Excitation, project report, Air Force Geophysics Laboratory, Hanscom AFB, MA, USA, 200 pp., 1982.

Forbes, J. M. and $\mathrm{Wu}$, D.: Solar Tides as Revealed by Measurements of Mesosphere Temperature by the MLS Experiment on UARS, J. Atmos. Sci., 63, 1776-1797, https://doi.org/10.1175/JAS3724.1, 2006.

Fritts, D. C. and Alexander, M. J.: Gravity wave dynamics and effects in the middle atmosphere, Rev. Geophys., 41, 1003, https://doi.org/10.1029/2001RG000106, 2003.

Gelaro, R., McCarty, W., Suárez, M. J., Todling, R., Molod, A., Takacs, L., Randles, C. A., Darmenov, A., Bosilovich, M. G., Reichle, R., Wargan, K., Coy, L., Cullather, R., Draper, C., Akella, S., Buchard, V., Conaty, A., Da Silva, A. M., Gu, W., Kim, G.K., Koster, R., Lucchesi, R., Merkova, D., Nielsen, J. E., Partyka, G., Pawson, S., Putman, W., Rienecker, M., Schubert, S. D., Sienkiewicz, M., and Zhao, B.: The Modern-Era Retrospective Analysis for Research and Applications, Version 2 (MERRA-2), J. Climate, 30, 5419-5454, https://doi.org/10.1175/JCLI-D-160758.1, 2017.

Global Modeling and Assimilation Office (GMAO): MERRA2 tavg3_3d_asm_Nv: 3d, 3-Hourly, Time-Averaged, Model-Level, Assimilation, Assimilated Meteorological Fields V5.12.4, Greenbelt, MD, USA, Goddard Earth Sciences Data and Information Services Center (GES DISC), https://doi.org/10.5067/SUOQESM06LPK (accessed: 28 November 2017), 2015.

Hann, J.: Untersuchungen über die tägliche Oscillation des Barometers: Die dritteltägige (achtstündige) Luftdruckschwankung, Denkschr. Akad. Wiss. Wien, 95, 1-64, 1918 (in German).

Hauf, T., Finke, U., Neisser, J., Bull, G., and Stangenberg, J.-G.: A Ground-Based Network for Atmospheric Pressure Fluctuations, J. Atmos. Ocean. Tech., 13, 1001-1023, 1996.

Haurwitz, B.: The geographical distribution of the semidiurnal solar pressure oscillation, N.Y. University Meteor. Papers, New York, 2, $36 \mathrm{pp}, 1956$.

Haurwitz, B.: The Diurnal Surface-Pressure Oscillation, Arch. Met. Geoph. Biokl. A., 14, 361-379, https://doi.org/10.1007/BF02253483, 1965.

Haurwitz, B. and Cowley, A. D.: The lunar barometric tide, its global distribution and annual variation, Pure Appl. Geophys., 77, 122-150, https://doi.org/10.1007/BF00876008, 1969.

Haurwitz, B. and Cowley, A. D.: The Diurnal and Semidiurnal Barometric Oscillations, Global Distribution and Annual Variation, Pure Appl. Geophys., 102, 193-222, https://doi.org/10.1007/BF00876607, 1973.

Hedlin, M. A. H., Alcoverro, B., and D'Spain, G.: Evaluation of rosette infrasonic noise-reducing spatial filters, J. Acoust. Soc. Am., 114, 1807-1820, https://doi.org/10.1121/1.1603763, 2003.
Hoinka, K. P.: Semi-diurnal pressure fluctuation in the ERA40 Data, Meteorol. Z., 16, 255-260, https://doi.org/10.1127/09412948/2007/0213, 2007.

Kertz, W.: Components of the semidiurnal pressure oscillation, Sci. Rep. 4, Dept. of Meteor. and Ocean, New York University, New York, NY, USA, 1956.

Kohyama, T. and Wallace, J. M.: Lunar gravitational atmospheric tide, surface to $50 \mathrm{~km}$ in a global, gridded data set, Geophys. Res. Lett., 41, 8660-8665, https://doi.org/10.1002/2014GL060818, 2014.

Le Pichon, A., Blanc, E., and Drob, D. P.: Probing high-altitude winds using infrasound, J. Geophys. Res.-Atmos., 110, D20104, https://doi.org/10.1029/2005JD006020, 2005.

Le Pichon, A., Ceranna, L., Pilger, C., Mialle, P., Brown, D. J., Herry, P., and Brachet, N.: The 2013 Russian fireball largest ever detected by infrasound sensors, Geophys. Res. Lett., 40, 37323737, https://doi.org/10.1002/grl.50619, 2013.

Le Pichon, A., Assink, J. D., Heinrich, P., Blanc, E., CharltonPerez, A., Lee, C. F., Keckhut, P., Hauchecorne, A., Rüfenacht, R., Kämpfer, N., Drob, D. P., Smets, P. S. M., Evers, L. G., Ceranna, L., Pilger, C., Ross, O., and Claud, C.: Comparison of co-located independent ground-based middle atmospheric wind and temperature measurements with numerical weather prediction models, J. Geophys. Res.-Atmos., 120, 8318-8331, https://doi.org/10.1002/2015JD023273, 2015.

Lindzen, R. S. and Chapman, S.: Atmospheric Tides, Space Sci. Rev., 10, 3-188, 1969.

Lomb, N. R.: Least-Squares Frequency Analysis of Unequally Spaced Data, Astrophys. Space Sci., 39, 447-462, 1976.

MARTEC: MB2005, User Manual, Ref. 14643-B, Martec Tekelec Systèmes, Les Ulis, France, 2006.

Marty, J., Ponceau, D., and Dalaudier, F.: Using the International Monitoring System infrasound network to study gravity waves, Geophy. Res. Lett., 37, L19802, https://doi.org/10.1029/2010GL044181, 2010.

Moudden, Y. and Forbes, J. M.: A decade-long climatology of terdiurnal tides using TIMED/SABER observations, J. Geophys. Res.-Space, 118, 4534-4550, https://doi.org/10.1002/jgra.50273, 2013.

Oberheide, J., Hagan, M. E., Richmond, A. D., and Forbes, J. M.: Dynamical Meteorology: Atmospheric Tides, Encyclopedia of Atmospheric Sciences, 2nd Edition, 2, 287-297, https://doi.org/10.1016/B978-0-12-382225-3.00409-6, 2015.

Pilger, C., Ceranna, L., Ross, J. O., Le Pichon, A., Mialle, P., and Garces, M.: CTBT infrasound network performance to detect the 2013 Russian fireball event, Geophys. Res. Lett., 42, 2523-2531, https://doi.org/10.1002/2015GL063482, 2015.

Ponceau, D. and Bosca, L.: Low-Noise Broadband Microbarometers, in: Infrasound Monitoring for Atmospheric Studies, edited by: Le Pichon, A., Blanc, E., Hauchecorne, A., Springer, Dordrecht, the Netherlands, 119-140, https://doi.org/10.1007/978-14020-9508-5_4, 2010.

Pramanik, S. K.: The six-hourly variations of atmospheric pressure and temperature, Mem. R. Metrol. Soc., 1, 35-57, 1926.

Ray, R. D. and Ponte, R. M.: Barometric tides from ECMWF operational analyses, Ann. Geophys., 21, 1897-1910, https://doi.org/10.5194/angeo-21-1897-2003, 2003. 
Ray, R. D. and Poulose, S.: Terdiurnal Surface-Pressure Oscillations over the Continental United States, Mon. Weather Rev., 133, 2526-2534, https://doi.org/10.1175/MWR2988.1, 2005.

Scargle, J. D.: Studies in Astronomical Time Series Analysis II. Statistical Aspects of Spectral Analysis of Unevenly Spaced Data, Astrophys. J., 263, 835-853, 1982.

Schindelegger, M. and Dobslaw, H.: A global ground truth view of the lunar air pressure tide $\mathrm{L}_{2}$, J. Geophys. Res.-Atmos., 121, 95110, https://doi.org/10.1002/2015JD024243, 2016.

Schindelegger, M. and Ray, R. D.: Surface Pressure Tide Climatologies Deduced from a Quality-Controlled Network of Barometric Observations, Mon. Weather Rev., 142, 4872-4889, https://doi.org/10.1175/MWR-D-14-00217.s1, 2014.

Smets, P. S. M. and Evers, L. G.: The life cycle of a sudden stratospheric warming from infrasound ambient noise observations, J. Geophys. Res.-Atmos., 119, 12084-12099, https://doi.org/10.1002/2014JD021905, 2014.

Smith, A., Lott, N., and Vose, R.: The Integrated Surface Database: Recent Developments and Partnerships, B. Am. Meteorol. Soc., 92, 704-708, https://doi.org/10.1175/2011BAMS3015.1, 2011.

Thayaparan, T.: The terdiurnal tide in the mesosphere and lower thermosphere over London, Canada $\left(43^{\circ} \mathrm{N}, 81^{\circ} \mathrm{W}\right)$, J. Geophys. Res., 102, 695-708, https://doi.org/10.1029/97JD01839, 1997.

Thomson, W.: 2. On the Thermodynamic Acceleration of the Earth's Rotation, P. Roy. Soc. Edinb., 11, 396-405, https://doi.org/10.1017/S037016460004757X, 1882.

Torrence, C. and Compo, G. P.: A Practical Guide to Wavelet Analysis, B. Am. Meteorol. Soc., 79, 61-78, 1998.
Van Den Dool, H. M., Saha, S., Schemm, J., and Huang, J.: A temporal interpolation method to obtain hourly atmospheric surface pressure tides in Reanalysis 1979-1995, J. Geophys. Res., 102, 22013-22024, https://doi.org/10.1029/97JD01571, 1997.

Whiteman, C. D. and Bian, X.: Solar Semidiurnal Tides in the Troposphere: Detection by Radar Profilers, B. Am. Meteorol. Soc., 77, 529-542, https://doi.org/10.1175/15200477(1996)077<0529:SSTITT>2.0.CO;2, 1996.

WMO: Measurement of Atmospheric Pressure, in: Guide to Meteorological Instruments and Methods of Observation (CIMO guide), Part I: Measurement of Meteorological Variables, WMONo. 8, World Meteorological Organization, Geneva, Switzerland, 89-124, 2014.

WMO: Observation Components of the Global Observing System, available at: http://www.wmo.int/pages/prog/www/OSY/ Gos-components.html\#surface, last access: 7 March 2018a.

WMO: Observing Systems Capability Analysis and Review Tool: Surface, available at: https://oscar.wmo.int/surface, last access: 7 March 2018b.

Zhao, G., Liu, L., Ning, B., Wan, W., and Xiong, J.: The terdiurnal tide in the mesosphere and lower thermosphere over Wuhan $\left(30^{\circ} \mathrm{N}, 114^{\circ} \mathrm{E}\right)$, Earth Planets Space, 57, 393-398, https://doi.org/10.1186/BF03351823, 2005. 